\title{
Epidermal growth factor receptor (EGFR) is an independent adverse prognostic factor in esophageal adenocarcinoma patients treated with cisplatin-based neoadjuvant chemotherapy
}

\author{
Michaela Aichler ${ }^{1}$, Martin Motschmann ${ }^{1}$, Uta Jütting ${ }^{2}$, Birgit Luber $^{3}$, Karen Becker ${ }^{3}$, \\ Katja Ott' ${ }^{4}$, Florian Lordick ${ }^{5}$, Rupert Langer ${ }^{3}$, Marcus Feith $^{6}$, Jörg Rüdiger Siewert ${ }^{7}$ \\ and Axel Walch ${ }^{1}$ \\ ${ }^{1}$ Research Unit Analytical Pathology- Institute of Pathology, Helmholtz Zentrum München, German Research Center for \\ Environmental Health, Ingolstaedter Landstraße 1, Neuherberg, Germany \\ 2 Institute of Computational Biology, Helmholtz Zentrum München, German Research Center for Environmental Health, \\ Ingolstaedter Landstraße 1, Neuherberg, Germany \\ ${ }^{3}$ Institute of Pathology, Technische Universität München, Trogerstraße 18, München, Germany \\ ${ }^{4}$ Department of Surgery, University Hospital of Heidelberg, Im Neuenheimer Feld 110, Heidelberg, Germany \\ ${ }^{5}$ University Cancer Center Leipzig, University Clinic Leipzig, Liebigstraße 20, Leipzig, Germany \\ ${ }^{6}$ Department of Surgery, Klinikum rechts der Isar, Technische Universität München, Ismaninger Straße 22, München, \\ Germany \\ 7 Directorate, University of Freiburg, Hugstetter Straße 55, 79106 Freiburg, Germany \\ Correspondence to: Axel Walch email: axel.walch@helmholtz-muenchen.de \\ Keywords: EGFR, prognosis, chemotherapy, cisplatin, esophageal cancer \\ Received: May 16, $2014 \quad$ Accepted: July 26, $2014 \quad$ Published: July 26, 2014
}

This is an open-access article distributed under the terms of the Creative Commons Attribution License, which permits unrestricted use, distribution, and reproduction in any medium, provided the original author and source are credited.

\section{ABSTRACT}

Neoadjuvant platin-based therapy is accepted as a standard therapy for advanced esophageal adenocarcinoma (EAC). Patients who respond have a better survival prognosis, but still a significant number of responder patients die from tumor recurrence. Molecular markers for prognosis in neoadjuvantly treated EAC patients have not been identified yet. We investigated the epidermal growth factor receptor (EGFR) in prognosis and chemotherapy resistance in these patients. Two EAC patient cohorts, either treated by neoadjuvant cisplatin-based chemotherapy followed by surgery $(n=86)$ or by surgical resection $(n=46)$ were analyzed for EGFR protein expression and gene copy number. Data were correlated with clinical and histopathological response, disease-free and overall survival.

In case of EGFR overexpression, the prognosis for neoadjuvant chemotherapy responders was poor as in non-responders. Responders had a significantly better disease-free survival than non-responders only if EGFR expression level $(p=0.0152)$ or copy number $(p=0.0050)$ was low. Comparing neoadjuvantly treated patients and primary resection patients, tumors of non-responder patients more frequently exhibited EGFR overexpression, providing evidence that EGFR is a factor for indicating chemotherapy resistance.

EGFR overexpression and gene copy number are independent adverse prognostic factors for neoadjuvant chemotherapy-treated EAC patients, particularly for responders. Furthermore, EGFR overexpression is involved in resistance to cisplatinbased neoadjuvant chemotherapy. 


\section{INTRODUCTION}

Esophageal adenocarcinoma (EAC) is among the most rapidly increasing malignancies in the western world [1-3]. Despite improvement in surgical outcomes, the prognosis for EAC remains dismal with less than $20 \%$ of patients surviving 5 years [2]. Neoadjuvant chemo- or radiochemotherapy followed by resection has been shown to provide a survival benefit for patients with locally advanced EAC compared to surgery alone [4-7]. A common therapeutic approach for these EAC is a multimodal treatment that includes preoperative application of cis-diamminedichloroplatinum II (cisplatin) and 5-flurouracil (5-FU) chemotherapy, followed by resection [4, 6-9]. Patients who respond to the neoadjuvant chemotherapy have a better survival [9-11]. Response evaluation for EAC treatment can be performed according to metabolic response evaluation using fluordeoxyglucose positron emission tomography, clinical response evaluation by endoscopy, endoluminal ultrasound and computed tomography (CT) scans, or histopathological response evaluation following resection. Until now, the histological response evaluation has been considered the gold standard [12,13], and these results are strongly associated with survival [14-16]. It is generally accepted that patients with a primary tumor response have a significantly improved prognosis compared to patients who do not respond [17]; however, despite a positive histological response, a significant percentage of patients still die due to tumor recurrence $[16,18,19]$. The reasons for this remains unclear, and effective tools to predict the clinical course of patients treated with neoadjuvant chemotherapy are missing. The Union for International Cancer Control/American Joint Committee on Cancer (UICC/AJCC) TNM classification ( $7^{\text {th }}$ edition) provides a good prognostic stratification for primary resected esophageal cancer, but the accuracy of this current classification in neoadjuvant chemotherapy-treated EAC remains largely unknown [13]. Therefore molecular markers that may determine the prognosis in neoadjuvant chemotherapy-treated EAC patients are urgently needed.

The epidermal growth factor receptor (EGFR) pathway has been recognized as one of the key proliferative pathways that is dysregulated during tumorigenesis, and this pathway is a major regulator of various signaling pathways involved in cell survival, migration, and tissue regeneration [20]. In adenocarcinomas of the esophagogastric junction (AEG) and the distal esophagus, EGFR expression has been found in approximately $30-60 \%$ $[21,22]$, while EGFR gene amplification has been found in $8-31 \%[23,24]$. Although an association of EGFR expression or EGFR gene amplification with poor prognosis in primary resection patients has been proposed $[21,25]$, the clinical and biological significance of such expression in neoadjuvantly treated patients remain undefined. To further elucidate the role of EGFR in EAC, we examined the EGFR protein expression and gene copy number changes, clinical characteristics, and outcome in EAC patients treated with cisplatin-based neoadjuvant chemotherapy. We hypothesized that EGFR in EAC promotes an aggressive tumor phenotype and results in poor outcomes and neoadjuvant chemotherapy resistance.

\section{RESULTS}

\section{Correlation of EGFR protein expression, copy number changes, and clinical variables}

Tissue samples of 86 patients who underwent neoadjuvant chemotherapy and 46 samples of patients treated by primary resection without chemotherapy were examined for EGFR protein expression and gene copy number changes (EGFR-to-chromosome-7 ratio) (Table 1). EGFR expression and copy number changes were significantly positively correlated in neoadjuvant chemotherapy-treated patients $(\mathrm{p}<0.0001)$ and primary resection patients $(\mathrm{p}=0.0057)$. High EGFR protein expression (IHC score $2+/ 3+$ ) occurred in $31.4 \%$ of patients who received neoadjuvant chemotherapy. In contrast, only $13.0 \%$ of patients in the primary resection group demonstrated high EGFR protein expression (Table 1). The number of patients with an EGFR gene copy number amplification (EGFR-to-chromosome-7 ratio of $>2.2$ ) in neoadjuvant chemotherapy-treated patients $(4.7 \%)$ was comparable to that in the primary resection patient group (4.3\%; Table 1$)$.

\section{EGFR overexpression is an independent adverse prognostic factor in EAC patients}

EGFR protein expression was significantly associated with outcome in the whole population including neoadjuvant treated and primary resected patients (Figure 1, Table 2). In the neoadjuvant treated group, EGFR protein expression was significantly associated with disease-free survival ( $\mathrm{p}=0.0194$; Figure 1A, Table 2). In primary resection patients, a significant association between EGFR protein expression and disease-free survival $(p<0.0001$; Figure 1G, Table 2$)$ and overall survival ( $<<0.0001$; Figure $1 \mathrm{H}$, Table 2$)$ was identified. Further stratification of the neoadjuvant chemotherapy group into responding and non-responding patients revealed that survival of patients who did not respond to chemotherapy was not associated with EGFR expression (Figure 1E-F, Table 2). In contrast, disease-free and overall survival of responding patients were significantly associated with the EGFR expression status (Figure 1C-D, Table 2). Responding patients with low EGFR expression profit significantly in terms of disease-free $(\mathrm{p}=0.0015$; Figure $1 \mathrm{C}$, Table 2$)$ and overall survival $(\mathrm{p}=0.0032$; Figure 


\begin{tabular}{|c|c|c|c|c|c|c|}
\hline \multirow{3}{*}{\begin{tabular}{|l} 
Talde l: Chanas \\
\\
\end{tabular}} & \multirow{2}{*}{\multicolumn{3}{|c|}{$\begin{array}{l}\text { EGFR } \\
\text { IHC Seore }\end{array}$}} & \multicolumn{3}{|c|}{ EGFR/Chromosome-7 ratio } \\
\hline & & & & \multirow[b]{2}{*}{$\leq 2.2$} & \multirow[b]{2}{*}{$>2.2$} & \multirow[b]{2}{*}{ total } \\
\hline & $0 / 1+$ & $2+/ 3+$ & total & & & \\
\hline \multicolumn{7}{|c|}{ Neoadjuvant chemotherayy-treated EAC (cT3/cT4) } \\
\hline \multicolumn{7}{|c|}{ Numlerer of patients } \\
\hline \multirow[t]{2}{*}{\begin{tabular}{|l|} 
Total \\
\end{tabular}} & 59 & 27 & 86 & 82 & 4 & 86 \\
\hline & $(68.6 \%)$ & $(31.4 \%)$ & & $(95.3 \%)$ & $(4.7 \%)$ & \\
\hline \multicolumn{7}{|l|}{ Tumor stage } \\
\hline \multirow[t]{2}{*}{ ypT 1} & 5 & 0 & 5 & 5 & 0 & 5 \\
\hline & $(100.0 \%)$ & $(0.0 \%)$ & & $(100.0 \%)$ & $(0.0 \%)$ & \\
\hline ypT2 & 15 & 6 & 21 & 19 & 1 & 20 \\
\hline & $(71.4 \%)$ & $(28.6 \%)$ & & $(95.0 \%)$ & $(5 . \% \%)$ & \\
\hline $\mathrm{ypT}^{2}$ & 30 & 17 & 47 & 45 & 2 & 47 \\
\hline & $(63.8 \%)$ & $(36.2 \%)$ & & $(95.7 \%)$ & $(4.3 \%)$ & \\
\hline Lymph node me & astasis & & & & & \\
\hline $\mathrm{ypN0}$ & 17 & 4 & 21 & 21 & 0 & 21 \\
\hline & $(81.0 \%)$ & $(190 \%)$ & & $(100.0 \%)$ & $(0.0 \%)$ & \\
\hline $\mathrm{ypN}_{\mathrm{N}}$ & 33 & 19 & 52 & 49 & 3 & 52 \\
\hline & $\langle 63,5 \% 9$ & $(36.5 \%)$ & & $(94.2 \%)$ & $(5.8 \%)$ & \\
\hline Distant metastas & & & & & & \\
\hline M0 & 45 & 21 & 66 & 63 & 3 & 66 \\
\hline & $(68.1 \%)$ & $(31.9 \%)$ & & $(95.6 \%)$ & $(4.4 \%)$ & \\
\hline Ml & 5 & 2 & 7 & 7 & 0 & 7 \\
\hline & $(71.4 \%)$ & $(28,6 \%)$ & & $(100.0 \%)$ & $(0.0 \%)$ & \\
\hline Rescetion & & & & & & \\
\hline RO & 40 & 18 & 58 & 56 & 3 & 59 \\
\hline & $(69.0 \%)$ & $(31.0 \%)$ & & $(94.9 \%)$ & $(5.1 \%)$ & \\
\hline Rl & 10 & 3 & 13 & 12 & 0 & 12 \\
\hline & $(76.9 \%)$ & $(23.1 \%)$ & & $(100.0 \%)$ & $(0.0 \%)$ & \\
\hline $\mathrm{R} 2$ & 0 & 2 & 2 & 2 & 0 & 2 \\
\hline & $(0,0 \%)$ & $(100,0 \%)$ & & $(100,0 \%)$ & $(0.0 \%)$ & \\
\hline ypUICC & & & & & & \\
\hline 1 & 3 & 0 & 3 & 3 & 0 & 3 \\
\hline & $(100.0 \%)$ & $(0.0 \%)$ & & $(100.0 \%)$ & $(0.0 \%)$ & \\
\hline 2 & 13 & 4 & 17 & 16 & 0 & 16 \\
\hline & $(76.5 \%)$ & $(23.5 \%)$ & & $(100.0 \%)$ & $(0.0 \%)$ & \\
\hline 3 & 8 & 3 & 11 & 10 & 1 & 11 \\
\hline & $(72.7 \%)$ & $(27.3 \%)$ & & $(90.9 \%)$ & $(9.1 \%)$ & \\
\hline 4 & 21 & 14 & 35 & 33 & 2 & 35 \\
\hline & $(60.0 \%)$ & $(40.0 \%)$ & & $(94.3 \%)$ & $(5.7 \%)$ & \\
\hline 5 & 5 & 2 & 7 & 7 & 0 & 7 \\
\hline & $(71.4 \%)$ & $(28.6 \%)$ & & $(100.0 \%)$ & $(0 . \% \%)$ & \\
\hline Responder & 15 & 4 & 19 & 18 & 1 & 19 \\
\hline & $(78.9 \%)$ & $(21.1 \%)$ & & $(94,7 \%)$ & $(5.3 \%)$ & \\
\hline Non-responder & 33 & 17 & 50 & 49 & 1 & 50 \\
\hline & $(66.0 \%)$ & $(34.0 \%)$ & & $(98.0 \%)$ & $(2.0 \%)$ & \\
\hline & & Primary res & lion EA & (cT3) & & \\
\hline $\begin{array}{l}\text { Number of } \\
\text { patients }\end{array}$ & & & & & & \\
\hline Total & 40 & 6 & 46 & 44 & 2 & 46 \\
\hline & $(87.0 \%)$ & $(13.0 \%)$ & & (95.7\%) & $(4.3 \%)$ & \\
\hline Tumor stage & & & & & & \\
\hline pT3 (tolal) & 40 & 6 & 46 & 44 & 2 & 46 \\
\hline & $(87.0 \%)$ & $(13.0 \%)$ & & $(95.7 \%)$ & $(4.3 \%)$ & \\
\hline Lymph node me & astasis & & & & & \\
\hline $\mathrm{pNO}$ & 10 & 0 & 10 & 10 & 0 & 10 \\
\hline & $(100.0 \%)$ & $0 \%$ & & $(100.0 \%)$ & $(0.0 \%)$ & \\
\hline $\mathrm{pN} 1$ & 30 & 6 & 36 & 34 & 2 & 36 \\
\hline & $(83.3)$ & $(16.7 \%)$ & & $(94.4 \%)$ & $(5.6 \%)$ & \\
\hline Distant metistas & & & & & & \\
\hline Mo & 36 & 4 & 40 & 39 & 1 & 40 \\
\hline & $(90.0 \%)$ & $(10.0 \%)$ & & $(97.5 \%)$ & $2.5 \%)$ & \\
\hline MI & 4 & 2 & 6 & 5 & 1 & 6 \\
\hline & $(66.7 \%)$ & $(33.3 \%)$ & & $(83,3 \%)$ & $(16,7)$ & \\
\hline Resection & & & & & & \\
\hline $\mathrm{R} 0$ & 26 & 1 & 27 & 27 & 0 & 27 \\
\hline & $(96.3 \%)$ & $(3,7 \%)$ & & $(100.0 \%)$ & $(0,0 \%)$ & \\
\hline $\mathrm{Rl}$ & 13 & 4 & 17 & 16 & l & 17 \\
\hline & $(76.5 \%)$ & $(23.5 \%)$ & & $(94.1 \%)$ & $(5.9 \%)$ & \\
\hline $\mathrm{R} 2$ & 0 & l & 1 & 1 & 0 & 1 \\
\hline & $(0.0 \%)$ & $(100.0 \%)$ & & $(100.0 \%)$ & $(0.0 \%)$ & \\
\hline
\end{tabular}


Table 2: Correlation of EGFR protein expression and copy number changes with patient survival data

\begin{tabular}{|l|l|l|l|l|}
\hline & \multicolumn{2}{|l|}{ EGFR } & \multicolumn{2}{l|}{ EGFR/Cep7 } \\
\hline & \multicolumn{2}{|l|}{ protein expression } & \multicolumn{2}{l|}{ Ratio } \\
\hline & EGFR-low vs EGFR-high & \multicolumn{2}{l|}{$\leq 2.2$ vs $>2.2$} \\
\hline & $\mathrm{P}$ & $\mathrm{n}=$ & $\mathrm{P}$ & $\mathrm{n}=$ \\
\hline Disease-free survival & & & & \\
\hline $\begin{array}{l}\text { Neoadjuvant chemotherapy-treated EAC } \\
\text { (cT3/cT4) }\end{array}$ & 0.0194 & 71 & 0.7531 & 71 \\
\hline Responder & 0.0015 & 19 & 0.0359 & 19 \\
\hline Non-responder & 0.5295 & 43 & 0.6685 & 43 \\
\hline Primary resection EAC (cT3) & $<0.0001$ & 46 & 0.8006 & 46 \\
\hline Overall survival & & & & \\
\hline $\begin{array}{l}\text { Neoadjuvant chemotherapy-treated EAC } \\
\text { (cT3/cT4) }\end{array}$ & 0.0829 & 73 & 0.3820 & 73 \\
\hline Responder & 0.0032 & 19 & 0.0359 & 19 \\
\hline Non-responder & 0.9086 & 43 & 0.4451 & 43 \\
\hline Primary resection EAC (cT3) & $<0.0001$ & 46 & 0.7494 & 46 \\
\hline
\end{tabular}

Table 3: Stepwise Cox regression analysis and hazard ratios of disease-free and overall survival with prognostic factors in neoadjuvant chemotherapy-treated and primary resection EAC patients

\begin{tabular}{|c|c|c|c|c|}
\hline & Univariate & Multivariate & HR & 95\% Confidence Intervals \\
\hline \multicolumn{5}{|l|}{ Disease-free survival } \\
\hline \multicolumn{5}{|c|}{ Neoadjuvant chemotherapy-treated EAC } \\
\hline UICC staging & 0.0001 & 0.0002 & 1.848 & $1.339-2.551$ \\
\hline \multicolumn{5}{|l|}{ Responder } \\
\hline EGFR protein expression & 0.0082 & 0.0050 & 24.004 & $2.612-220.622$ \\
\hline ypM & $<0.0001$ & 0.0036 & 58.135 & $3.785-892.811$ \\
\hline \multicolumn{5}{|l|}{ Non-responder } \\
\hline ypM & 0.0236 & 0.0309 & 2.942 & $1.104-7.839$ \\
\hline \multicolumn{5}{|l|}{ Primary resection EAC } \\
\hline $\mathrm{R}$ & 0.0459 & 0.0208 & 2.414 & $1.144-5.095$ \\
\hline ypN & 0.0300 & 0.0140 & 3.329 & $1.275-8.690$ \\
\hline EGFR protein expression & 0.0258 & 0.0296 & 1.994 & $1.071-3.716$ \\
\hline \multicolumn{5}{|l|}{ Overall survival } \\
\hline \multicolumn{5}{|c|}{ Neoadjuvant chemotherapy-treated EAC } \\
\hline ypM & $<0.0001$ & 0.0243 & 3.557 & $1.179-10.734$ \\
\hline EGFR protein expression & 0.0491 & 0.0483 & 1.962 & $1.005-3.829$ \\
\hline UICC staging & 0.0451 & 0.0488 & 1.512 & $1.002-2.282$ \\
\hline \multicolumn{5}{|l|}{ Responder } \\
\hline ypM & 0.0012 & 0.0017 & 45.854 & $4.206-499.865$ \\
\hline EGFR protein expression & 0.0037 & 0.0033 & 13.466 & $2.383-76.078$ \\
\hline \multicolumn{5}{|l|}{ Non-responder } \\
\hline UICC staging & 0.0095 & 0.0016 & 2.303 & $1.371-3.869$ \\
\hline \multicolumn{5}{|l|}{ Primary resection EAC } \\
\hline $\mathrm{R}$ & 0.0131 & 0.0047 & 3.111 & $1.415-6.838$ \\
\hline ypN & 0.0205 & 0.0137 & 3.578 & $1.298-9.862$ \\
\hline EGFR protein expression & 0.0405 & 0.0448 & 1.899 & $1.015-3.555$ \\
\hline
\end{tabular}

Abbreviation: HR, hazard ratio 
1D, Table 2), while high EGFR expression significantly shortened survival in this subgroup (Figure 1C-D, Table 2).

Multivariate Cox regression analysis confirmed EGFR overexpression as an independent adverse prognostic factor for disease-free survival $(\mathrm{p}=0.0050$; $\mathrm{HR}=24.004 ; 95 \%$ confidence intervals (CI), 2.612$220.622)$ and overall survival $(\mathrm{p}=0.0033 ; \mathrm{HR}=13.466$; 95\% CI, 2.383-76.078) in patients who responded to neoadjuvant chemotherapy (Table 3 ). This effect was also observed in primary resection EAC patients with respect to disease-free $(\mathrm{p}=0.0296 ; \mathrm{HR}=1.994 ; 95 \% \mathrm{CI}, 1.071-$ $3.716)$ and overall survival $(\mathrm{p}=0.0448 ; \mathrm{HR}=1.899 ; 95 \%$ CI, 1.015-3.555; Table 3).

Thus, EGFR protein expression is an independent adverse prognostic factor, in particular, patients who respond to neoadjuvant chemotherapy can be stratified into patients with a good survival prognosis with low EGFR protein expression and patients with a poor survival prognosis with high EGFR protein expression.

\section{EGFR protein expression}
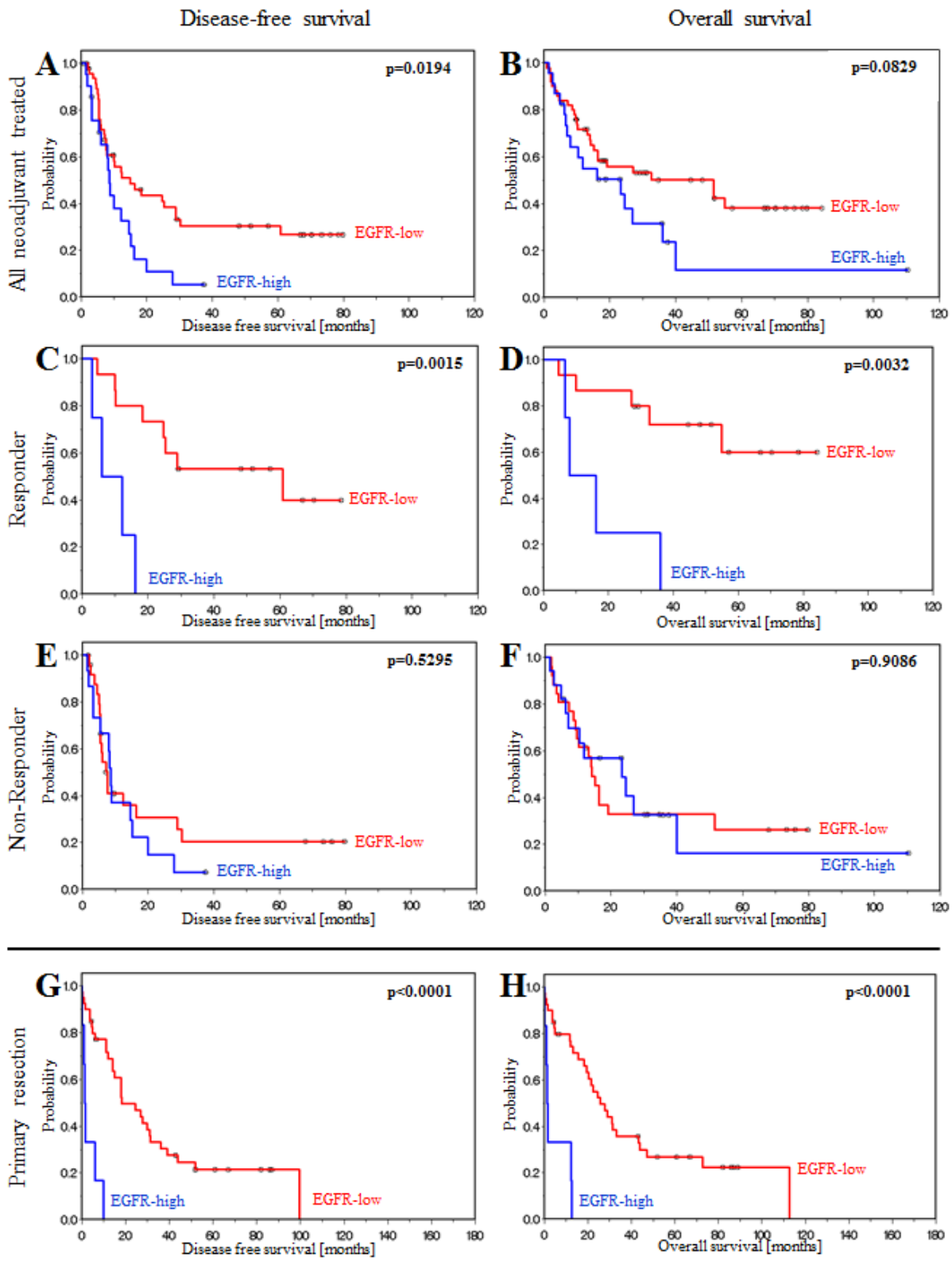

Figure 1: EGFR protein expression is associated with prognosis in patients treated with neoadjuvant chemotherapy or primary resection. (A) Disease-free and (B) overall survival of all neoadjuvant chemotherapy-treated patients. (C) Disease-free and (D) overall survival of responding patients. (E) Disease-free and (F) overall survival of non-responding patients. (G) Disease-free and $(\mathrm{H})$ overall survival of primary resection patients. Patients can be stratified as patients with a good survival prognosis if EGFR protein expression is low and patients with a poor survival prognosis if EGFR protein expression is high. 
We further evaluated the influence of EGFR protein expression in neoadjuvant chemotherapy-treated patients as a molecular factor for survival prognosis. A statistically significant association between low EGFR expression levels (EGFR-low) and disease-free survival $(\mathrm{p}=0.0152)$ and overall survival ( $\mathrm{p}=0.0036)$ was noted in responders and non-responders (Figure 2A), although responders had a significantly better prognosis than non-responders. In cases where patients did not respond to chemotherapy but had low EGFR protein expression, after surviving the first two years after therapy, their disease-free and overall survival was as good as that for responder patients. In contrast to these findings, in patients with high EGFR expression, the prognosis for responders was as poor as that for non-responders (Figure 2C). Thus, neoadjuvant therapy responders with a putative good prognosis were identified as actually having a poor prognosis after neoadjuvant therapy according to EGFR overexpression.

We also evaluated these findings with regard to copy number changes (EGFR-to-chromosome-7 ratio) and obtained similar results. A statistically significant difference was observed in responders and non-responders
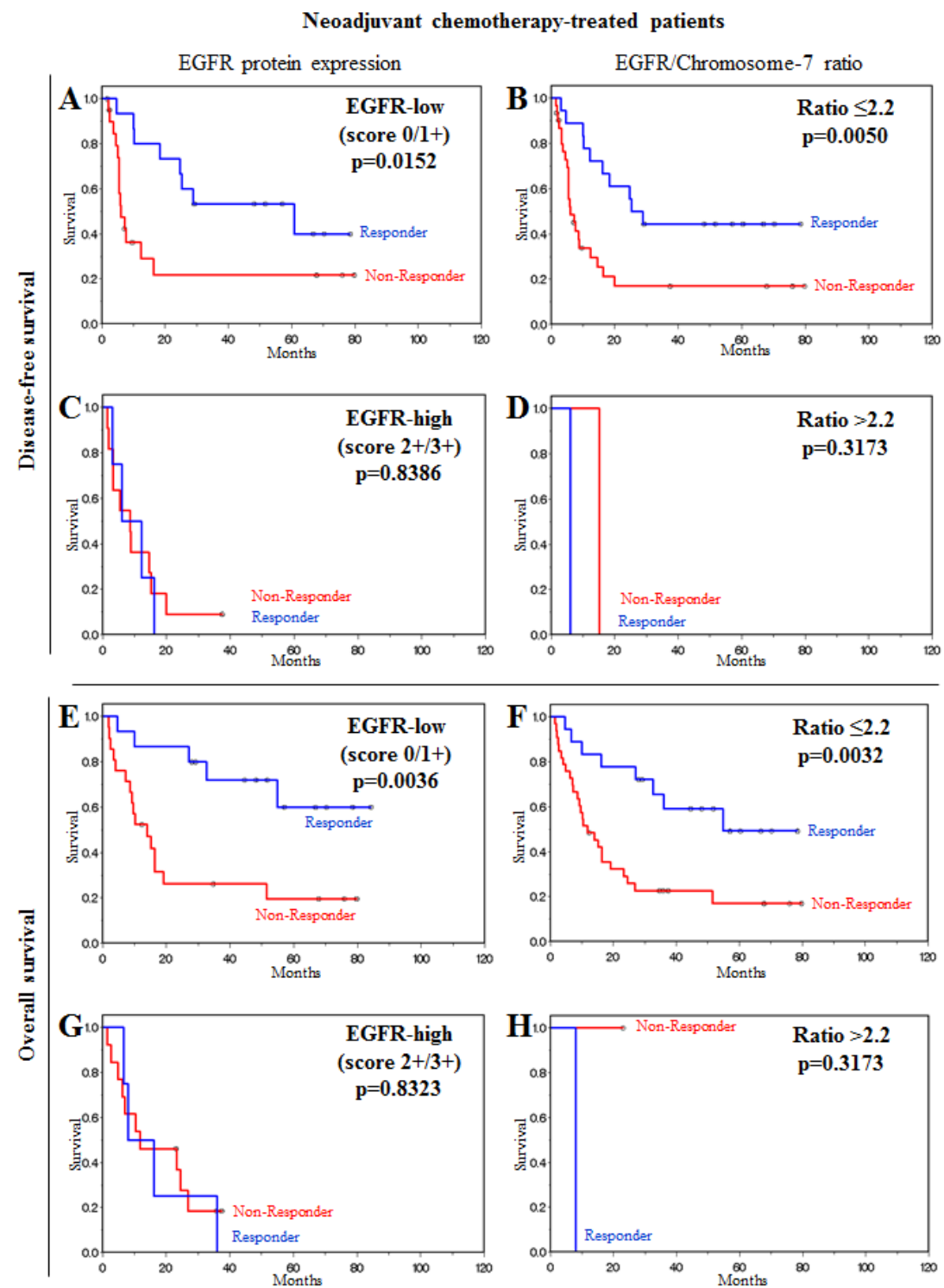

Figure 2: EGFR overexpression and $E G F R /$ Chromosome-7 ratio are molecular factors for stratification of patients after neoadjuvant chemotherapy. (A, B, C, D) Disease-free survival of neoadjuvant chemotherapy-treated patients. (A) Low EGFR protein expression. (B) Low $E G F R /$ Chromosome-7 ratio. (C) High EGFR protein expression. (D) High EGFR/Chromosome-7 ratio. (E, F, $\mathrm{G}, \mathrm{H}$ ) Overall survival of neoadjuvant chemotherapy-treated patients. (E) Low EGFR protein expression. (F) Low EGFR/Chromosome-7 ratio. (G) High EGFR protein expression. (H) High EGFR/Chromosome-7 ratio. Prognosis for neoadjuvant chemotherapy responders was as poor as that for non-responders when EGFR expression level was high. Responders had a significantly better prognosis than nonresponders when EGFR expression level or EGFR/Chromosome-7 ratio were low. 
between disease-free survival $(\mathrm{p}=0.0050)$ and overall survival $(\mathrm{p}=0.0032)$ and patients who did not have an EGFR amplification (Figure 2B), and a significantly better prognosis was predicted for responders than for non-responders. Identification of responder patients with a poor prognosis as for EGFR-high patients was not possible using FISH analysis in patients with an EGFRto-chromosome-7 ratio $>2.2$ due to limitations in patient numbers (Figure 2D).

\section{Comparison of clinical, histopathological response, and EGFR expression as factors for prognosis}

We examined EGFR protein expression with respect to clinical and histopathological response evaluation as a factor for prognosis in the neoadjuvant chemotherapytreated patient group. Multivariate $\mathrm{COX}$ regression analysis revealed that EGFR protein expression was the strongest prognostic factor for disease-free survival $(\mathrm{p}=0.0218 ; \mathrm{HR}=2.010 ; 95 \%$ CI, 1.107-3.650), while histopathological response was the strongest factor for overall survival $(\mathrm{p}=0.0018 ; \mathrm{HR}=3.626 ; 95 \% \mathrm{CI}, 1.613-$ 8.154).

\section{Comparison of EGFR overexpression in neoadjuvant chemotherapy and primary resection EAC patients}

The frequency of EGFR overexpression in patients who respond to neoadjuvant chemotherapy was compared with the frequency of EGFR overexpression in EAC patients treated with primary resection without chemotherapy. The percentage of cases with high EGFR expression levels (score $2+$ or $3+$ ) was significantly more often found $(\mathrm{p}=0.0108)$ in the neoadjuvant chemotherapytreated cohort $(31.4 \%, 27$ of 86 vs. $13.0 \%, 6$ of 46$)$ compared to the primary resection cohort (Table 1). To further assess these findings, we separately compared the responder and the non-responder subgroup with the primary resection cohort. No significant difference in the frequency of EGFR overexpression was detected between chemotherapy-responders and in primary resection patients ( $p=0.2028$; Figure $3 \mathrm{~A}$ ). In contrast, the frequency of EGFR overexpression, was significantly higher in nonresponders than in primary resection patients $(\mathrm{p}=0.0107$; Figure 3B).

\section{DISCUSSION}

Neoadjuvant platinum-based chemotherapy is a standard treatment regimen for patients with advanced EAC $[4,7]$. It is generally accepted that patients who respond to neoadjuvant chemotherapy have a survival benefit $[10,11]$; however, despite a positive histological response, a significant number of patients die from tumor recurrence $[16,18,19]$. Therapeutic response of patients often do not prolong patient survival [26]. This might be due to current therapies eliminate abundant cancer cells but do not target stem cells [26]. In a review of concept, Blagosklonny pointed out further explanations [27]. The response-survival paradox could be explained as effective therapy selects for resistance among proliferating cancer cells [27]. Mechanisms of resistance might be either based nononcogenic (e.g. drug transporters and mutation in drug-targets) or oncogenic (e.g. apoptosis and cell cycle dysregulation) [27]. The oncogenic resistance is associated with highly aggressive cancer phenotype and, therefore no survival benefit [27]. The above mentioned theories might give an explanation for tumor recurrence in responding EAC patients. In the current study, we investigated EGFR in prognosis and chemotherapy resistance esophageal adenocarcinoma patients with a positive response to therapy but who died from tumor recurrence. EGFR, a receptor tyrosine kinases, is a major regulator of signaling pathways involved in cell survival, migration, and tissue regeneration [20]. Several studies have demonstrated that EGFR expression is a strong prognostic indicator that correlates with both higher recurrence rates and shorter survival in different tumor entities [21, 25, 28-30]. Additionally, studies on the EGFR status as a prognostic factor in patients treated by neoadjuvant chemotherapy have been reported [31-33]. These studies have yielded contradictory results across different cancer types [3133]. In a recently published study, EGFR overexpression was useful in predicting response in patients with triple-negative breast cancer treated with neoadjuvant chemotherapy [33]. In an earlier study of triple-negative breast cancer, patients with EGFR-positive had a less favorable prognosis and a poorer response to neoadjuvant chemotherapy than patients with EGFR-negative tumors [32]. On the other hand, in patients with locally advanced rectal cancer treated with preoperative chemoradiotherapy, $E G F R$ gene copy number was neither predictive nor prognostic [31]. A few studies have investigated EGFR expression in EAC patients, but these studies have focused on prognosis in patients with primary resection of EAC or AEG. Although in these studies EGFR was associated with poor overall survival, a consistent association between EGFR and an adverse outcome was not yet substantiated $[21,25,29,30,34]$. The new finding in our study is, that EGFR expression predicted poorer survival outcomes in a subgroup of EAC patients with initial histopathologic response to chemotherapy. To the best of our knowledge, this was not yet studied before in any other population. In addition, in our study population of primary resection patients, EGFR expression was a strong and independent prognostic factor for disease-free and overall survival. A recently published study investigated factors that predict prognosis and recurrence in patients with esophagogastric 
adenocarcinoma and a histopathological response with less than $10 \%$ residual tumor [18]. Response of the primary tumor did not ensure recurrence-free long-term survival, although complete histopathological responders had a better prognosis compared to partial responders [18]. Another recently published study defined a multifactorial histopathological score based on ypT category, ypN, and degree of histological tumor regression for the prediction of prognosis of resected EAC after cisplatin-based neoadjuvant chemotherapy [35]. Our data, however, demonstrated that EGFR expression or copy number changes are strong and independent molecular prognostic factors for disease-free and overall survival in patients with EAC who responded to neoadjuvant chemotherapy but had an unfavorable diagnosis.

Cisplatin is a DNA-damaging anti-tumor agent that activates nuclear as well as cytoplasmic signaling pathways involved in regulation of the cell cycle, damage repair, and programmed cell death [36]. EGFR expression may be involved in resistance to cisplatin [37, 38]. The signals generated by DNA damage caused by cisplatin treatment modulate EGFR activity in EGFRexpressing cells and suppress cell death by upregulating antiapoptotic proteins [37]. In addition, inhibition of EGFR activation enhances cisplatin-induced cell death [37]. Overexpression of EGFR and inhibition of proliferation has been observed in cisplatin-treated ovarian carcinoma cells, and these molecular changes were hypothesized to be an escape mechanism of tumor cells [39]. Another study demonstrated that treatment of chemosensitive neuroblastoma cells with cisplatin reversibly increased EGFR expression and that cisplatinresistant cells exhibited enhanced EGFR expression dependent of the presence of cisplatin [40]. In squamous cell carcinoma cells, increased EGF signaling and subsequent increased interleukin (IL)-1ß contributed to chemotherapeutic resistance [41]. Furthermore, acquired cisplatin resistance in EGFR-expressing lung cancer cells did not affect the sensitivity to EGFR tyrosine kinase inhibitors [42]. Together, these studies demonstrate that EGFR may be involved in mechanism of resistance to cisplatin. In the present study, we compared the frequency of EGFR overexpression in primary resection patients to neoadjuvant chemotherapy responders and non-responders. In the non-responding subgroup, EGFR expression was significantly higher than that in chemotherapy responders as well as in the primary resection patients. These findings provide evidence that EGFR overexpression is a factor for chemotherapy resistance and supports the hypothesis that EGFR is involved in the mechanism of resistance against cisplatinbased neoadjuvant chemotherapy.

Resistance can be exploited for therapeutic advantage [43, 44]. Evolving from several decades of systematic research in cancer cell biology, several EGFR inhibitors, such as monoclonal antibodies and tyrosine kinase inhibitors have been developed and implemented in clinical application [45]. The efficacy of cetuximab in combination with chemotherapy was evaluated as a firstline treatment of advanced gastric and gastro-esophageal junction cancer [46-49]. The overall results of these studies revealed response rates between 41 and $65 \%$.

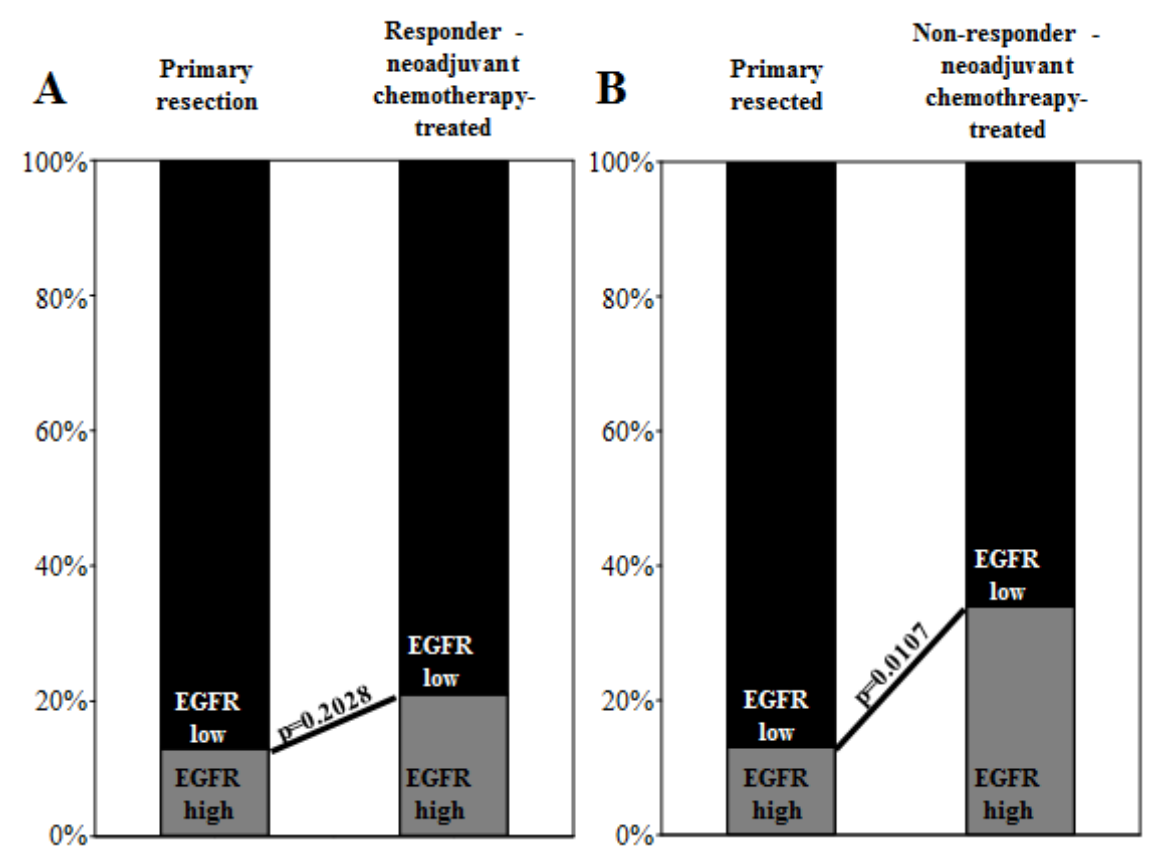

Figure 3: Bar graphs depict EGFR expression level distribution (EGFR-high vs. EGFR-low) in comparisons of primary resection patients with neoadjuvant chemotherapy (A) responders and (B) non-responders. EGFR overexpression is more frequent in nonresponding patients, and thus, this overexpression can be interpreted as a factor for chemotherapy resistance. 
The efficacy of cetuximab plus capecitabin and cisplatin was subsequently tested in a multinational randomized phase III trial for the first-line treatment of patients with advanced gastric and gastro-esophageal junction cancer (EXPAND, NCT00678535) [50]. The addition of cetuximab to capecitabine-cisplatin provided no additional benefit to chemotherapy alone in the first-line treatment of advanced gastric or gastro-esophageal junction cancer; however, this study did not specifically focus on AEG 1 patients. Therefore, studies on the effect of EGFR-directed therapy in AEG 1 patients have been missing but may be of interest in the neoadjuvant chemotherapy setting especially for EGFR-positive patients.

In conclusion, our data demonstrate that EGFR overexpression and gene copy number changes are independent adverse prognostic factors in EAC patients and may be useful molecular markers for outcome prediction in patients who receive neoadjuvant platinbased chemotherapy.

\section{PATIENTS, MATERIALS AND METHODS}

\section{Study population}

In this study, a total of 132 patients with EAC (all classified as type I according to Siewert [51]) were included. The patients were staged as cT3 or cT4 based on endoscopic ultrasonography and CT of the chest and abdomen. The study population consisted of two different treatment groups: one was treated with cisplatin-based neoadjuvant chemotherapy and the second was treated by primary resection without neoadjuvant chemotherapy. All patients provided written informed consent, and patient data were acquired with approval from the ethics committee of the Technische Universität München, Germany. For all patients, surgical resection material (formalin-fixed paraffin-embedded tissue) was available.

\section{Neoadjuvant chemotherapy cohort}

Patients $(n=86)$ were treated with neoadjuvant chemotherapy consisting of two cycles of cisplatin on days 1,15 , and 29 and folinic acid plus fluorouracil on days 1 , $8,15,22,29$, and 36 , all repeated on day 49 , as previously described in detail [52].

\section{Primary resection cohort}

Patients $\quad(n=46)$ underwent primary abdominothoracic esophagectomy [53] without chemotherapy or radiotherapy. For comparison with the neoadjuvant chemotherapy-treated patient group, only patients staged as cT3 were included in the study.

\section{Response evaluation and follow-up}

Tumor response to neoadjuvant chemotherapy was characterized clinically and histopathologically.

Clinical response was evaluated by endoscopy with endoluminal ultrasound and CT scan after the first and second cycle as described previously [54]. Response was defined as at least $50 \%$ reduction in the size of the primary tumor, as measured by endoscopy and imaging studies [55].

Histopathological tumor regression was assessed according to a recently published scoring system [56]. For the purposes of this study, all patients with fewer than $10 \%$ residual tumor cells (regression score 1) were classified as responders. All other patients were classified as histopathological non-responders.

Patient follow-up included endoscopy and CT of the chest and abdomen at 3-month intervals during the first year after surgery and thereafter at 6-month intervals. Overall survival and disease-free survival were calculated from the day of surgery. Survival analyses for the primary resection cohort were calculated from all 46 patients with a median follow-up of 19.9 months (range, 0.1 to 134.0 months) for overall survival and 14.5 months (range, 0.1 to 134.0 months) for disease-free survival. For the neoadjuvant chemotherapy-treated cohort, median followup was 17.0 months for overall survival (range, 0.8 to 110.4 months) and 9.2 months for disease-free survival (range, 0.1 to 79.8 months). The observation time was the interval between diagnosis and last contact (death or last follow-up).

\section{Tissue microarrays}

Three representative areas of the tumor (1.0 $\mathrm{mm}$ diameter) were removed from paraffin-embedded tissue blocks, which had been prepared at the time of resection, using a tissue microarray instrument (Beecher Instruments, Sun Prairie, Wisconsin, USA). Serial sections were cut for the purpose of immunohistochemistry (IHC) and transferred to adhesive slides using the "paraffin-tapetransfer-system" according to manufacturer's instructions (Instrumedics, Hackensack, NJ, USA).

\section{Fluorescence in situ hybridization (FISH), evaluation, and image analysis}

A commercially available assay with fluorescencelabeled locus-specific DNA probes for EGFR and chromosome-7 centromeric $\alpha$-satellite (Chrombios) was hybridized with the samples according to a previously described protocol [57]. The hybridization specificity of the probes was tested with metaphase spreads, and lymphocytes served as internal controls in tumor tissue 
samples. Signal evaluation was performed by visual counting using an epifluorescence microscope equipped with a C-Apochromat $63 \mathrm{x} / \mathrm{NA} 1.2 \mathrm{~W}$ objective and an AxioCam b/w charge-coupled device camera (Zeiss Axioplan 2, Carl Zeiss Microimaging GmbH; AxioVision software release 4.5) according to standard procedures. At least 50 tumor cells per case were selected randomly, whereas only cells with a minimum of one signal for $E G F R$ gene and centromere-7 were chosen, and the mean was calculated. FISH scoring for EGFR-to-chromosome-7 ratio was applied, and two categories were determined: mean ratios of $\leq 2.2$ and $>2.2$. Ratios $\leq 2.2$ were designated as non-amplified, while ratios $>2.2$ were designated as EGFR amplification.

\section{Immunohistochemical analysis and reactivity score}

EGFR immunohistochemistry was performed using the Dako EGFRpharmDx ${ }^{\mathrm{TM}}$ assay detection system (Dako Diagnostika GmbH, Hamburg, Germany) as described previously [58]. Tumors were considered to be negative when no staining or membrane staining in $<10 \%$ neoplastic cells was observed. Weak complete and/or incomplete membrane staining in $>10 \%$ neoplastic cells was considered as $1+$ positive, while moderate complete and/or incomplete membrane staining in $>10 \%$ neoplastic cells was considered as $2+$ positive. Strong complete and/ or incomplete membrane staining in $>10 \%$ neoplastic cells was considered as $3+$ positive. Cases with a score of 0 or $1+$ were considered as EGFR-low expression cases, while those with a score of $2+$ or $3+$ were considered overexpression (EGFR-high) cases.

\section{Statistical Analysis}

Correlations between variables were calculated using the Pearson correlation coefficient. Frequency tables were tested by $\chi^{2}$ test or Fisher exact test for comparison of discrete variables. Stepwise Cox regression analysis was applied to select parameters for predicting the overall survival time or disease-free survival time, their calculated hazard ratio are listed. Kaplan-Meier survival curves for different strata were plotted for overall survival and disease-free survival. The differences were tested by the log-rank test. All statistical tests were performed with SAS statistical package version 9.2 (SAS Institute Inc., Cary, $\mathrm{NC}$ ), and significance was determined at the 95\% level.

\section{ACKNOWLEDGEMENTS}

We thank Sandra Rauser and Daniel Veith for their contribution in data acquisition and Ulrike Buchholz, Claudia-Mareike Pflüger, Gabriele Mettenleiter, and Andreas Voss for excellent technical assistance.

\section{GRANT SUPPORT}

The study was supported by Ministry of Education and Research of the Federal Republic of Germany (BMBF) (SYS-Stomach: 01ZX1310B) to AW, BL, FL, and the Deutsche Forschungsgemeinschaft (Grant Nos SFB 824 TP Z02 and WA 1656/3-1) to AW.

\section{CONFLICT OF INTEREST}

The authors declare that they have no conflicts of interest.

\section{REFERENCES}

1. Ajani JA, Barthel JS, Bentrem DJ, D'Amico TA, Das P, Denlinger CS, Fuchs CS, Gerdes H, Glasgow RE, Hayman JA, Hofstetter WL, Ilson DH, Keswani RN, Kleinberg LR, Korn WM, Lockhart AC, et al. Esophageal and esophagogastric junction cancers. J Natl Compr Canc Netw. 2011; 9(8):830-887.

2. Siegel R, Naishadham D and Jemal A. Cancer statistics, 2013. CA Cancer J Clin. 2013; 63(1):11-30.

3. Pohl H, Sirovich B and Welch HG. Esophageal adenocarcinoma incidence: are we reaching the peak? Cancer Epidemiol Biomarkers Prev. 2010; 19(6):14681470 .

4. Cunningham D, Allum WH, Stenning SP, Thompson JN, Van de Velde CJ, Nicolson M, Scarffe JH, Lofts FJ, Falk SJ, Iveson TJ, Smith DB, Langley RE, Verma M, Weeden S, Chua YJ and Participants MT. Perioperative chemotherapy versus surgery alone for resectable gastroesophageal cancer. N Engl J Med. 2006; 355(1):11-20.

5. Siewert JR, Lordick F, Ott K, Stein HJ, Weber WA, Becker K, Peschel C, Fink U and Schwaiger M. Induction chemotherapy in Barrett cancer: influence on surgical risk and outcome. Ann Surg. 2007; 246(4):624-628; discussion 628-631.

6. van Hagen P, Hulshof MCCM, van Lanschot JJB, Steyerberg EW, Henegouwen MIV, Wijnhoven BPL, Richel DJ, Nieuwenhuijzen GAP, Hospers GAP, Bonenkamp JJ, Cuesta MA, Blaisse RJB, Busch ORC, ten Kate FJW, Creemers GJ, Punt CJA, et al. Preoperative Chemoradiotherapy for Esophageal or Junctional Cancer. New England Journal of Medicine. 2012; 366(22):20742084.

7. Ychou M, Boige V, Pignon JP, Conroy T, Bouche O, Lebreton G, Ducourtieux M, Bedenne L, Fabre JM, SaintAubert B, Geneve J, Lasser P and Rougier P. Perioperative chemotherapy compared with surgery alone for resectable gastroesophageal adenocarcinoma: an FNCLCC and FFCD multicenter phase III trial. J Clin Oncol. 2011; 29(13):17151721.

8. Lordick F, Holscher AH, Haustermans $\mathrm{K}$ and Wittekind C. 
Multimodal treatment of esophageal cancer. Langenbecks Arch Surg. 2013; 398(2):177-187.

9. Schauer M, Stein H, Lordick F, Feith M, Theisen J and Siewert JR. Results of a multimodal therapy in patients with stage IV Barrett's adenocarcinoma. World J Surg. 2008; 32(12):2655-2660.

10. Becker K, Fumagalli U, Mueller JD, Fink U, Siewert JR and Hofler H. Neoadjuvant chemotherapy for patients with locally advanced gastric carcinoma: effect on tumor cell microinvolvement of regional lymph nodes. Cancer. 1999; 85(7):1484-1489.

11. Walsh TN, Noonan N, Hollywood D, Kelly A, Keeling N and Hennessy TP. A comparison of multimodal therapy and surgery for esophageal adenocarcinoma. N Engl J Med. 1996; 335(7):462-467.

12. Langer R, Ott K, Feith M, Lordick F, Siewert JR and Becker K. Prognostic significance of histopathological tumor regression after neoadjuvant chemotherapy in esophageal adenocarcinomas. Mod Pathol. 2009; 22(12):1555-1563.

13. Schmidt T, Sicic L, Blank S, Becker K, Weichert W, Bruckner T, Parakonthun T, Langer R, Buchler MW, Siewert JR, Lordick F and Ott K. Prognostic value of histopathological regression in 850 neoadjuvantly treated oesophagogastric adenocarcinomas. Br J Cancer. 2014; 110(7):1712-1720.

14. Schneider PM, Baldus SE, Metzger R, Kocher M, Bongartz R, Bollschweiler E, Schaefer H, Thiele J, Dienes HP, Mueller RP and Hoelscher AH. Histomorphologic tumor regression and lymph node metastases determine prognosis following neoadjuvant radiochemotherapy for esophageal cancer: implications for response classification. Ann Surg. 2005; 242(5):684-692.

15. Ott K, Weber WA, Lordick F, Becker K, Busch R, Herrmann K, Wieder H, Fink U, Schwaiger M and Siewert JR. Metabolic imaging predicts response, survival, and recurrence in adenocarcinomas of the esophagogastric junction. J Clin Oncol. 2006; 24(29):4692-4698.

16. Vallbohmer D, Holscher AH, DeMeester S, DeMeester T, Salo J, Peters J, Lerut T, Swisher SG, Schroder W, Bollschweiler E and Hofstetter W. A multicenter study of survival after neoadjuvant radiotherapy/chemotherapy and esophagectomy for ypT0N0M0R0 esophageal cancer. Ann Surg. 2010; 252(5):744-749.

17. Lowy AM, Mansfield PF, Leach SD, Pazdur R, Dumas P and Ajani JA. Response to neoadjuvant chemotherapy best predicts survival after curative resection of gastric cancer. Ann Surg. 1999; 229(3):303-308.

18. Ott K, Blank S, Becker K, Langer R, Weichert W, Roth W, Sisic L, Stange A, Jager D, Buchler M, Siewert JR and Lordick F. Factors predicting prognosis and recurrence in patients with esophago-gastric adenocarcinoma and histopathological response with less than $10 \%$ residual tumor. Langenbecks Arch Surg. 2013; 398(2):239-249.

19. Meredith KL, Weber JM, Turaga KK, Siegel EM,
McLoughlin J, Hoffe S, Marcovalerio M, Shah N, Kelley $\mathrm{S}$ and Karl R. Pathologic response after neoadjuvant therapy is the major determinant of survival in patients with esophageal cancer. Ann Surg Oncol. 2010; 17(4):11591167.

20. Brandt B, Meyer-Staeckling S, Schmidt H, Agelopoulos $\mathrm{K}$ and Buerger $\mathrm{H}$. Mechanisms of egfr gene transcription modulation: relationship to cancer risk and therapy response. Clin Cancer Res. 2006; 12(24):7252-7260.

21. Wang KL, Wu TT, Choi IS, Wang H, Resetkova E, Correa AM, Hofstetter WL, Swisher SG, Ajani JA, Rashid A and Albarracin CT. Expression of epidermal growth factor receptor in esophageal and esophagogastric junction adenocarcinomas: association with poor outcome. Cancer. 2007; 109(4):658-667.

22. Yacoub L, Goldman H and Odze RD. Transforming growth factor-alpha, epidermal growth factor receptor, and MiB1 expression in Barrett's-associated neoplasia: correlation with prognosis. Mod Pathol. 1997; 10(2):105-112.

23. Miller CT, Moy JR, Lin L, Schipper M, Normolle D, Brenner DE, Iannettoni MD, Orringer MB and Beer DG. Gene amplification in esophageal adenocarcinomas and Barrett's with high-grade dysplasia. Clin Cancer Res. 2003; 9(13):4819-4825.

24. al-Kasspooles M, Moore JH, Orringer MB and Beer DG. Amplification and over-expression of the EGFR and erbB-2 genes in human esophageal adenocarcinomas. Int J Cancer. 1993; 54(2):213-219.

25. Marx AH, Zielinski M, Kowitz CM, Dancau AM, Thieltges S, Simon R, Choschzick M, Yekebas E, Kaifi JT, Mirlacher M, Atanackovic D, Brummendorf TH, Fiedler W, Bokemeyer C, Izbicki JR and Sauter G. Homogeneous EGFR amplification defines a subset of aggressive Barrett's adenocarcinomas with poor prognosis. Histopathology. 2010; 57(3):418-426.

26. Huff CA, Matsui W, Smith BD and Jones RJ. The paradox of response and survival in cancer therapeutics. Blood. 2006; 107(2):431-434.

27. Blagosklonny MV. Why therapeutic response may not prolong the life of a cancer patient: selection for oncogenic resistance. Cell Cycle. 2005; 4(12):1693-1698.

28. Katoh K, Nakanishi Y, Akimoto S, Yoshimura K, Takagi M, Sakamoto $\mathrm{M}$ and Hirohashi S. Correlation between laminin-5 gamma2 chain expression and epidermal growth factor receptor expression and its clinicopathological significance in squamous cell carcinoma of the tongue. Oncology (Williston Park). 2002; 62(4):318-326.

29. Langer R, Von Rahden BH, Nahrig J, Von Weyhern C, Reiter R, Feith M, Stein HJ, Siewert JR, Hofler H and Sarbia M. Prognostic significance of expression patterns of c-erbB-2, p53, p16INK4A, p27KIP1, cyclin $\mathrm{D} 1$ and epidermal growth factor receptor in oesophageal adenocarcinoma: a tissue microarray study. J Clin Pathol. 2006; 59(6):631-634. 
30. Paterson AL, O’Donovan M, Provenzano E, Murray LJ, Coleman HG, Johnson BT, McManus DT, Novelli M, Lovat LB and Fitzgerald RC. Characterization of the timing and prevalence of receptor tyrosine kinase expression changes in oesophageal carcinogenesis. J Pathol. 2013; 230(1):118128.

31. Bengala C, Bettelli S, Bertolini F, Sartori G, Fontana A, Malavasi N, Depenni R, Zironi S, Del Giovane C, Luppi G and Conte PF. Prognostic role of EGFR gene copy number and KRAS mutation in patients with locally advanced rectal cancer treated with preoperative chemoradiotherapy. Br J Cancer. 2010; 103(7):1019-1024.

32. Nogi H, Kobayashi T, Suzuki M, Tabei I, Kawase K, Toriumi Y, Fukushima $\mathrm{H}$ and Uchida K. EGFR as paradoxical predictor of chemosensitivity and outcome among triple-negative breast cancer. Oncol Rep. 2009; 21(2):413-417.

33. Tang Y, Zhu L, Li Y, Ji J, Li J, Yuan F, Wang D, Chen W, Huang O, Chen X, Wu J, Shen K, Loo WT and Chow LW. Overexpression of epithelial growth factor receptor (EGFR) predicts better response to neo-adjuvant chemotherapy in patients with triple-negative breast cancer. J Transl Med. 2012; 10 Suppl 1:S4.

34. Bettstetter M, Berezowska S, Keller G, Walch A, Feuchtinger A, Slotta-Huspenina J, Feith M, Drecoll E, Hofler $\mathrm{H}$ and Langer R. Epidermal growth factor receptor, phosphatidylinositol-3-kinase catalytic subunit/PTEN, and KRAS/NRAS/BRAF in primary resected esophageal adenocarcinomas: loss of PTEN is associated with worse clinical outcome. Hum Pathol. 2012.

35. Langer R, Becker K, Zlobec I, Gertler R, Sisic L, Buchler M, Lordick F, Slotta-Huspenina J, Weichert W, Hofler H, Feith $\mathrm{M}$ and Ott K. A multifactorial histopathologic score for the prediction of prognosis of resected esophageal adenocarcinomas after neoadjuvant chemotherapy. Ann Surg Oncol. 2014; 21(3):915-921.

36. Cepeda V, Fuertes MA, Castilla J, Alonso C, Quevedo $\mathrm{C}$ and Perez JM. Biochemical mechanisms of cisplatin cytotoxicity. Anticancer Agents Med Chem. 2007; 7(1):318.

37. Benhar M, Engelberg D and Levitzki A. Cisplatininduced activation of the EGF receptor. Oncogene. 2002; 21(57):8723-8731.

38. Hsu SC, Miller SA, Wang Y and Hung MC. Nuclear EGFR is required for cisplatin resistance and DNA repair. Am J Transl Res. 2009; 1(3):249-258.

39. Lang T, Daxenbichler G and Marth C. Effects of cytostatic agents on the expression of epidermal growth factor receptor in ovarian cancer cells. Anticancer Res. 1994; 14(5A):1871-1874

40. Michaelis M, Bliss J, Arnold SC, Hinsch N, Rothweiler F, Deubzer HE, Witt O, Langer K, Doerr HW, Wels WS and Cinatl J, Jr. Cisplatin-resistant neuroblastoma cells express enhanced levels of epidermal growth factor receptor (EGFR) and are sensitive to treatment with EGFR-specific toxins. Clin Cancer Res. 2008; 14(20):6531-6537.

41. Ko SC, Huang CR, Shieh JM, Yang JH, Chang WC and Chen BK. Epidermal growth factor protects squamous cell carcinoma against cisplatin-induced cytotoxicity through increased interleukin-1beta expression. PLoS One. 2013; 8(2):e55795.

42. Rho JK, Choi YJ, Choi YR, Kim SY, Choi SJ, Choi CM, $\mathrm{Na}$, II and Lee JC. The effect of acquired cisplatin resistance on sensitivity to EGFR tyrosine kinase inhibitors in EGFR mutant lung cancer cells. Oncol Res. 2011; 19(10-11):471478.

43. Blagosklonny MV and Pardee AB. Exploiting cancer cell cycling for selective protection of normal cells. Cancer Res. 2001; 61(11):4301-4305.

44. Blagosklonny MV. Targeting cancer cells by exploiting their resistance. Trends Mol Med. 2003; 9(7):307-312.

45. Ciardiello F and Tortora G. EGFR antagonists in cancer treatment. N Engl J Med. 2008; 358(11):1160-1174.

46. Pinto C, Di Fabio F, Siena S, Cascinu S, Rojas Llimpe FL, Ceccarelli C, Mutri V, Giannetta L, Giaquinta S, Funaioli C, Berardi R, Longobardi C, Piana E and Martoni AA. Phase II study of cetuximab in combination with FOLFIRI in patients with untreated advanced gastric or gastroesophageal junction adenocarcinoma (FOLCETUX study). Ann Oncol. 2007; 18(3):510-517.

47. Pinto C, Di Fabio F, Barone C, Siena S, Falcone A, Cascinu S, Rojas Llimpe FL, Stella G, Schinzari G, Artale S, Mutri V, Giaquinta S, Giannetta L, Bardelli A and Martoni AA. Phase II study of cetuximab in combination with cisplatin and docetaxel in patients with untreated advanced gastric or gastro-oesophageal junction adenocarcinoma (DOCETUX study). Br J Cancer. 2009; 101(8):1261-1268.

48. Lordick F, Luber B, Lorenzen S, Hegewisch-Becker S, Folprecht G, Woll E, Decker T, Endlicher E, Rothling N, Schuster T, Keller G, Fend F and Peschel C. Cetuximab plus oxaliplatin/leucovorin/5-fluorouracil in first-line metastatic gastric cancer: a phase II study of the Arbeitsgemeinschaft Internistische Onkologie (AIO). Br J Cancer. 2010; 102(3):500-505.

49. Moehler M, Mueller A, Trarbach T, Lordick F, Seufferlein T, Kubicka S, Geissler M, Schwarz S, Galle PR, Kanzler $\mathrm{S}$ and German Arbeitsgemeinschaft Internistische $\mathrm{O}$. Cetuximab with irinotecan, folinic acid and 5-fluorouracil as first-line treatment in advanced gastroesophageal cancer: a prospective multi-center biomarker-oriented phase II study. Ann Oncol. 2011; 22(6):1358-1366.

50. Lordick F, Kang YK, Chung HC, Salman P, Oh SC, Bodoky G, Kurteva G, Volovat C, Moiseyenko VM, Gorbunova V, Park JO, Sawaki A, Celik I, Gotte H, Melezinkova H, Moehler M, et al. Capecitabine and cisplatin with or without cetuximab for patients with previously untreated advanced gastric cancer (EXPAND): a randomised, open-label phase 3 trial. Lancet Oncol. 2013; 14(6):490-499.

51. Siewert JR and Stein HJ. Classification of adenocarcinoma 
of the oesophagogastric junction. Br J Surg. 1998; 85(11):1457-1459.

52. Lordick F, Ott K, Krause BJ, Weber WA, Becker K, Stein HJ, Lorenzen S, Schuster T, Wieder H, Herrmann K, Bredenkamp R, Hofler H, Fink U, Peschel C, Schwaiger $\mathrm{M}$ and Siewert JR. PET to assess early metabolic response and to guide treatment of adenocarcinoma of the oesophagogastric junction: the MUNICON phase II trial. Lancet Oncol. 2007; 8(9):797-805.

53. Siewert JR, Stein HJ, Sendler A and Fink U. Surgical resection for cancer of the cardia. Semin Surg Oncol. 1999; 17(2):125-131.

54. Weber WA, Ott K, Becker K, Dittler HJ, Helmberger H, Avril NE, Meisetschlager G, Busch R, Siewert JR, Schwaiger $M$ and Fink U. Prediction of response to preoperative chemotherapy in adenocarcinomas of the esophagogastric junction by metabolic imaging. J Clin Oncol. 2001; 19(12):3058-3065.

55. Blank S, Lordick F, Bader F, Burian M, Dobritz M, Grenacher L, Becker K, Weichert W, Langer R, Sisic L, Stange A, Jager D, Buchler M, Bruckner T, Siewert $\mathrm{J}$ and Ott K. Post-therapeutic response evaluation by a combination of endoscopy and CT scan in esophagogastric adenocarcinoma after chemotherapy: better than its reputation. Gastric Cancer. 2014.

56. Becker K, Mueller JD, Schulmacher C, Ott K, Fink U, Busch R, Bottcher K, Siewert JR and Hofler H. Histomorphology and grading of regression in gastric carcinoma treated with neoadjuvant chemotherapy. Cancer. 2003; 98(7):1521-1530.

57. Walch A, Bink K, Hutzler P, Bowering K, Letsiou I, Zitzelsberger H, Braselmann H, Stein H, Hofler $\mathrm{H}$ and Werner M. Sequential multilocus fluorescence in situ hybridization can detect complex patterns of increased gene dosage at the single cell level in tissue sections. Lab Invest. 2001; 81(10):1457-1459.

58. Gamboa-Dominguez A, Dominguez-Fonseca C, Quintanilla-Martinez L, Reyes-Gutierrez E, Green D, Angeles-Angeles A, Busch R, Hermannstadter C, Nahrig J, Becker KF, Becker I, Hofler H, Fend F and Luber B. Epidermal growth factor receptor expression correlates with poor survival in gastric adenocarcinoma from Mexican patients: a multivariate analysis using a standardized immunohistochemical detection system. Mod Pathol. 2004; 17(5):579-587. 